\title{
Further Report on the Blood Platelet Count of Mothers with Different Arakawa's Reaction
}

\author{
126th Report of the Peroxidase Reaction.
}

\author{
By
}

Shizuo Kimura.

(木 村 槄 雄)

(From the Department of Pediatrics, Faculty of Medicine, Tohoku Imperial University, Sendai.

Director: Prof. A. Sato.)

\section{Introduction.}

Healthy mother's secreting milk negative* to Arakawa's reaction are, according to a number of papers published from this Laboratory, more or less in a state of Avitaminosis $\mathrm{B}^{* *}$ generally. Now it is well known that the blood platelet count increases remarkably in patients suffering from B-avitaminosis or beriberi. J. Kimura ${ }^{1 \text { ) }}$ 3) examined the blood platelet count of lactating mothers with different Arakawa's reaction and he found that the blood platelet count was high in apparently healthy mothers secreting Arakawa-negative milk, so that these mothers. were, he concluded, highly probably B-avitaminotic already.

I have also studied the relationship between the blood platelet count and A rakawa's reaction in lactating mothers and been able to confirm his results.

" "Arakawa-positive" may be used in two different senses. One of these is Arakawa-positive in biochemical sense. A sample of human milk is said to have become Arakawa-positive, when it became blue on the addition of A r a k w a r reagent. Here it means that the sample was not negative to A rakaw a's reaction. The other of these two senses is: Arakawa-positive in a clinical sense. A sample of human milk is clinically Arakawa-positive only when it shows such a reaction as $H$ or $H$ in one minute of the addition of Arakawa's reagent. Another sample of human milk may be Arakawa-positive in the first described sense, but yet clinically negative.

** $\mathrm{B}$ mean $\mathrm{B}_{1}$ throughout the article.

1) J. K im u r a, Tohoku J. Exp. Med., 1934, 23, 494.

2) J. K imura, Tokoku J. Exp. Med., 1935, 27, 360.

3) J. K im u ra, Tohoku J. Exp. Med., 1935, 27, 374: 


\section{Method of Investigation.}

1. Materials. Blood was taken from healthy lactating mothers of the breast-fed patients who visited our Dispensary.

2. Arakawa's reaction.

a. Milk was examined with A rakawa's reagent in each case.

b. I divided mother cases into 7 groups according to the intensity of Arakawa's reaction (Cf. Table 1 ).

\section{TABle 1.}

Grouping of cases according to the intesity of Arak awa's reaction of human milk.

\begin{tabular}{|c|c|c|c|}
\hline \multirow{3}{*}{ Group } & \multicolumn{3}{|c|}{ Intensity of A rakawa's reaction of human milk } \\
\hline & \multirow{2}{*}{$\begin{array}{c}\text { Arakawa-positive or -negative } \\
\text { in clinical sense }\end{array}$} & \multicolumn{2}{|c|}{ Expressed in signs } \\
\hline & & one side & the other side \\
\hline $\mathrm{I}$ & Arakawa-positive case (normal case) & $\begin{array}{l}(+\#) 1^{\prime} \\
(H) 1^{\prime}\end{array}$ & $\left\{\begin{array}{l}(+\#) 1^{\prime} \\
(++) 1^{\prime} \\
(+4) 1^{\prime}\end{array}\right.$ \\
\hline II & Arakawa-negative (or weakly-positive) case & $\begin{array}{l}(H) 1^{\prime} \\
(H) 1^{\prime}\end{array}$ & $\left\{\begin{array}{l}( \pm) \begin{array}{l}1^{\prime} \\
1^{\prime} \\
(+) \\
1^{\prime} \\
1^{\prime}\end{array}\end{array}\right.$ \\
\hline III & Arakawa-negative case & $\begin{array}{l}(+) 1^{\prime} \\
(+) 1^{\prime}\end{array}$ & $( \pm) \begin{array}{l}1^{\prime} \\
1^{\prime}\end{array}$ \\
\hline IV & $n$ & $\left(\begin{array}{l}+1^{\prime} \\
\pm( \pm) \\
1^{\prime}\end{array}\right.$ & $\left(\begin{array}{l}-1 \\
( \pm) 1^{\prime}\end{array}\right.$ \\
\hline $\mathrm{V}$ & $n$ & $\begin{array}{l}( \pm) 1^{\prime} \\
(-) 1^{\prime}\end{array}$ & 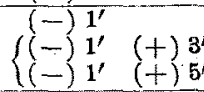 \\
\hline VI & Almost completely Arakawa-negative case & $(-) 5^{\prime}$ & $( \pm) 5^{\prime}$ \\
\hline VII & Completely Arakawa-negative case & $(-) 5^{\prime}$ & $(-) 5^{\prime}$ \\
\hline
\end{tabular}

Only Group I should be considered as normal in a clinical sense, and the others (Groups II, III, IV, V, VI and VII) are all of weak or negative A rakawa's reaction, thongh there are different classes among these negative groups.

c. The description of different A raka wa's reaction was simplified (Cf: Table 2).

3. Platelet count. I used L a m p ert's ${ }^{4)}$ method. The ear lobe was cleaned with ether, and a cut was made with Francke's needle. Blood was taken into the "A-thrombit" and diluted with Tyrode's solution. After shaking the pipette for a few minutes, the sixth drop of the contents was examined for blood platelets, waiting over five minutes after counting chamber was filled.

4) H. L a m pert, Verh. Dtsch. Ges. inn. Med., 1931, 43, 92. 


\section{TABLE 2.}

Table of signs for showing different A ralk aw a's reaction.

\section{$\begin{array}{lllll}1^{\prime} & 2^{\prime} & 3^{\prime} & 4^{\prime} & 5^{\prime}\end{array}$}

1. 1 (\#) stands for $\#$ \# H H H

2. $1(H)$ " H H H H H

3. $2(H)$ H H H H H

4. $3(H) \quad H+H+H$

5. $4(H) \quad$ H $+H+H$

6. $5(H), \quad H+H+H$

7. $1(+) \quad$ "

8. $2(+), \quad+$ H H H

9. $3(+) \quad+H+H+H$

10. $4(+), \quad+H+H+$

11. $5(t), \quad+++4+\#$

12. $6(t) "++4+4$

13. $7(+) "++$ H + H

14. $8(+) \quad$ $+++H+H$

15. $9(+), \quad+++H+H$

16. $10(t) " t+++H$

17. $11(+), \quad+++++$

18. 1 (土) $" \quad \pm+H+H$

19. $2( \pm), \quad$ 土 + H H

20. $3( \pm),, \quad \pm++H+$

21. $4( \pm) \quad$ $\quad \pm+++$ H

22. 5(士),$\pm++t+$

23. $6( \pm) \quad, \quad \pm++++$

24. $7( \pm) \quad, \quad \pm++++$
25. $\quad \begin{array}{lllll}1^{\prime} & 2^{\prime} & 3^{\prime} & 4^{\prime} & 5^{\prime}\end{array}$

25. $8( \pm)$ stands for $\pm \pm+H$ H

26. $9( \pm) \quad " \quad \pm \pm+H+$

27. $10( \pm) \quad n \quad \pm \pm+++$

28. $11( \pm) \quad n \quad \pm \pm+++$

29. $12( \pm) \quad, \quad \pm \pm \pm++$

30. $13( \pm) \quad, \quad \pm \pm \pm++$

31. 14 (土),$\quad \pm \pm \pm \pm+$

32. 15 (土),$\quad \pm \pm \pm \pm \pm$

33. 1 (-) " $\quad \pm+\mathrm{H}$

34. $2(-) \quad n- \pm+H+H$

35. $3(-) \quad " \quad++++$

36. $4(-) \quad " \quad- \pm+++$

37. 5(-) " $\quad- \pm \pm++$

38. $6(-) \quad, \quad- \pm \pm+t$

39. $7(-) \quad, \quad- \pm \pm \pm+$

40. $8(-) \quad, \quad- \pm \pm \pm \pm$

41. $9(-) \quad, \quad-- \pm+4$

42. $10(-), \quad- \pm+t$

43. $11(-) \quad$ " - \pm \pm+

44. $12(-) \quad, \quad-- \pm \pm \pm$

45. $13(-) \quad, \quad-\cdots- \pm+$

46. $14(-) \quad, \quad-- \pm \pm$

47. $15(-) \quad, \quad-\cdots-\cdots$

48. $16(-), \quad-\ldots+\cdots$

Explanation to the table :-

Take, for instance, the sign: $2(H)$. This stands for A rakawa's reaction with the course $(H) 1^{\prime}(H) 2^{\prime}(H) 3^{\prime}(H) 4^{\prime}(H) 5^{\prime}$. The sign does not express any prompt result of the reaction, so the prompt reaction of the sign: $2(7 t)$ may be $(-) 0^{\prime},( \pm) 0^{\prime}$, $(+) 0^{\prime}$ or even $(H) 0^{\prime}$, but this will not matter much, as the result of the reaction in one minute is the most important.

I examined the platelet count of 30 healthy unmarried women. Blood was taken about 11 o'clock a.m. They were as will be seen from Table 3 , of an averaged count of 314 thousands (Cf. Table 3). This count is far smaller than the

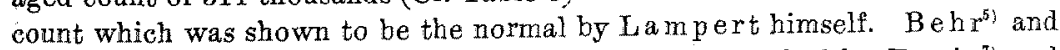
Baed or $f^{6)}$ compared the platelet count between the method by Fon i ${ }^{7)}$ and that by Lampert, and published the result that Lampert's method gives a slightly larger count than Fonio's method. Neither of these authors obtained so large figures as L a mpert showed to be the normal. Behr showed the average platelet count to be 210 thousands by Lampert's method and 167.8 thousands by Fonio's method in 10 healthy persons. Baed orf showed in 10 healthy persons 172 thousands by Lampert's method and 157.2 by Fonio's

5) C. H. Behr, Klin. Wschr., 1933, 12, 1771.

6) K. B a ed orf, Dtsch. med. Wschr., 1933, 59, 1643.

7) A. E o nio, Dtsch. Zschr. Chir., 1912, 177, 176. 
TABLE 3.

Blood platelet count in 30 healthy women.

\begin{tabular}{|c|c|c|c|c|c|c|c|c|c|}
\hline $\begin{array}{l}\text { Case } \\
\text { No. }\end{array}$ & Name & $\begin{array}{l}\text { Date of } \\
\text { experi- } \\
\text { ment }\end{array}$ & $\begin{array}{c}\text { Age } \\
\text { (years) }\end{array}$ & $\begin{array}{c}\text { Blood } \\
\text { platelet } \\
\text { count } \\
\text { (thousands) } \\
\text { per cmm. }\end{array}$ & $\begin{array}{l}\text { Case } \\
\text { No. }\end{array}$ & Name & $\begin{array}{l}\text { Date of } \\
\text { experi- } \\
\text { ment }\end{array}$ & $\begin{array}{c}\text { Age } \\
\text { (years) }\end{array}$ & $\begin{array}{c}\text { Blood } \\
\text { platelet } \\
\text { count } \\
\text { (thousands) } \\
\text { per cmm. }\end{array}$ \\
\hline 1 & T. . & 1. II & 28 & 400 & 16 & T.A. & 8. II & 26 & 260 \\
\hline 2 & C.T. & 1., & 30 & 340 & 17 & H.I. & 8. & 33 & 220 \\
\hline 3 & Y.T. & 2. & 23 & 220 & 18 & Y.O. & 9. & 31 & 310 \\
\hline 4 & J.N. & 2." & 24 & 270 & 19 & S. S. & 10. & 32 & 250 \\
\hline 5 & T.H. & $3, \pi$ & 19 & 240 & 20 & Y.T. & 10. $n$ & 28 & 380 \\
\hline 6 & T.Y. & 3. & 20 & 360 & 21 & A.A. & 12. & 19 & 260 \\
\hline 7 & T.M. & 3. & 31 & 390 & 22 & T.F. & 12. & 23 & 280 \\
\hline 8 & M.K. & 4. " & 20 & 500 & 23 & M.N. & 14. & 24 & 290 \\
\hline 9 & K.S. & 4. & 29 & 390 & 24 & M.K. & 26. " & 23 & 380 \\
\hline 10 & H.S. & 5. & 34 & 270 & 25 & Y.H. & 2. III & 26 & 310 \\
\hline 11 & K.I. & 5. & 24 & 360 & 26 & M.Y. & 4. & 20 & 200 \\
\hline 12 & H.O. & 5. & 20 & 300 & 27 & F.K. & 4. " & 19 & 240 \\
\hline 13 & S. T. & 7. & 20 & 500 & 28 & S.I. & 5. " & 21 & 310 \\
\hline 14 & F.K. & 7. " & 19 & 280 & 29 & F.H. & 5. " & 39 & 190 \\
\hline \multirow[t]{4}{*}{15} & T.M. & 7. & 32 & 350 & 30 & M.S. & 7. " & 28 & 370 \\
\hline & & & & & & & & Maxim & 500 \\
\hline & & & & & & & & Minimun & 190 \\
\hline & & & & & & & & Average & 314. \\
\hline
\end{tabular}

to be the average count. And Baed orf recommends the use of Lampert's thrombocyte counting method for its simplicity's sake. F o n i o showed the average count as 234 thousands and $\mathrm{Suzuki} \mathrm{i}^{87}$ of our Laboratory showed 200-300 thousands by Fonio's nethod to be the normal count. My results by Lampert's method was 314 thousands, which was reasonable if Fonio and Suzuki's counts are taken into consideration. At any rate, I always tried to use the same technique in all the cases examined, so that the counts might well be compared with each other in the present paper.

I classified all my cases into 4 groups according to their platelet count: the group with "no increase" (or with the platelet count of 200-400 thousands), the group with "slight increase" (or with the platelet count of 400-500 thousands), the group with "moderate increase" (or with the platelet count of 500600 thousands) and the group with "intense increase" (or with the platelet count of over 600 thousands).

\section{Results of Investigation.}

As will be seen from Tables 4,5,6,7,8,9 and 10, the total cases I examined were 266 lactating mothers. The range between the smallest and the largest count is very wide, from 210 thousand platelets to 760 thousands.

8) T. Suzuki, Tohoku J. Exp. Med, 1937, 30, 378. 
1. Group I: There were 27 cases belonging to Group I, namely, the group of mothers strongly or normally positive to A ra ka wa's reaction, and 23 eases $(85 \%)$ ) out of them showed a normal blood platelet count i.e. $200-400$ thousands. In only 4 cases (15\%) the blood platelet count was between 400 thousands and 500 thousands, showing a slight increase. The average count of blood platelets in Group I was 340 thousands (Cff. Table 4).

TABLE 4.

Blood platelet count of mothers belonging to Group $I$.

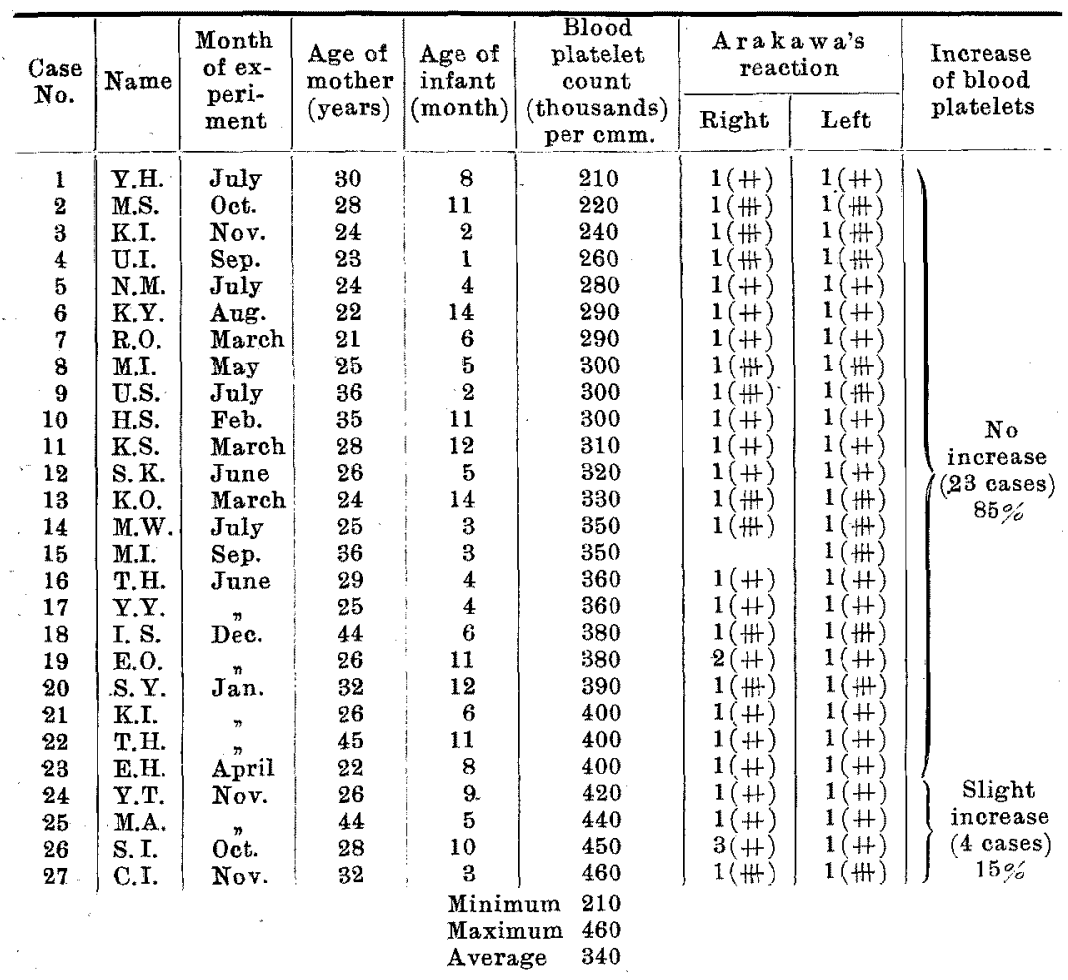

2. Group $\Pi$ : There were 13 cases belonging to Group II, and 7 cases (54\%) out of them showed a normal count, and in 5 cases (38\%) a slight increase was seen. There was only one case with a moderate increase. The blood platelet count in Group II was averaged 385 thousands (Cf. Table 5). 
TABLE 5.

Blood platelet count of mothers belonging to Group II.

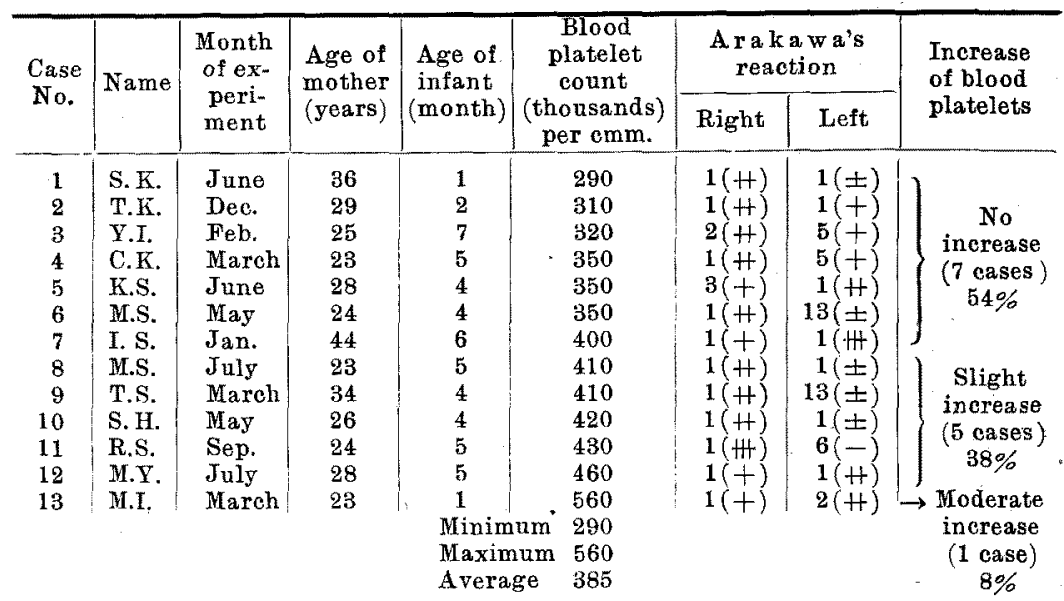

3. Group III : There were 33 cases belonging to Group III. Only 13 cases (40\%) out of them showed a normal platelet count, and in the other 20 cases $(60 \%)$ the count was increased. This relation was. different from that seen in the former two groups in that the majority showed.no increase. 8 cases (24\%) showed a slight increase, and 10 cases $(30 \%)$ a moderate increase. The remaining 2 cases $(6 \%)$ showed a rather intense increase. The average count in Group III was 447 thousands (Cf. Table 6 ).

4. Group IV : There were 33 cases belonging to Group IV. In 11 cases $(33 \%)$ the blood platelet count was normal and in the other 22 cases $(67 \%)$ an increase was seen. Namely, 11 cases $(33 \%)$ of them showed a slight increase of the count, 6 cases (19\%) a moderate increase and the remaining 5 cases $(15 \%)$ an intense increase of the count. The average platelet count was 470 thousands (Cf. Table 7).

5. Group V: There were 74 cases belonging to Group V. In only 16 cases (22\%) out of them the blood platelet count was normal and in the other 58 cases $(78 \%)$ an increase was seen. Namely, 25 cases (34\%) of them showed a slight increase of the count, 24 cases (32\%) a moderate increase and the remaining 9 cases $12 \%$ ) an intense increase. Cases with the platelet count over 510 thousands was $44 \%$ in this group. The average platelet count was 490 thousands (Cf. Table 8). 
TABLE 6.

Blood platelet count of mothers belonging to Group III.

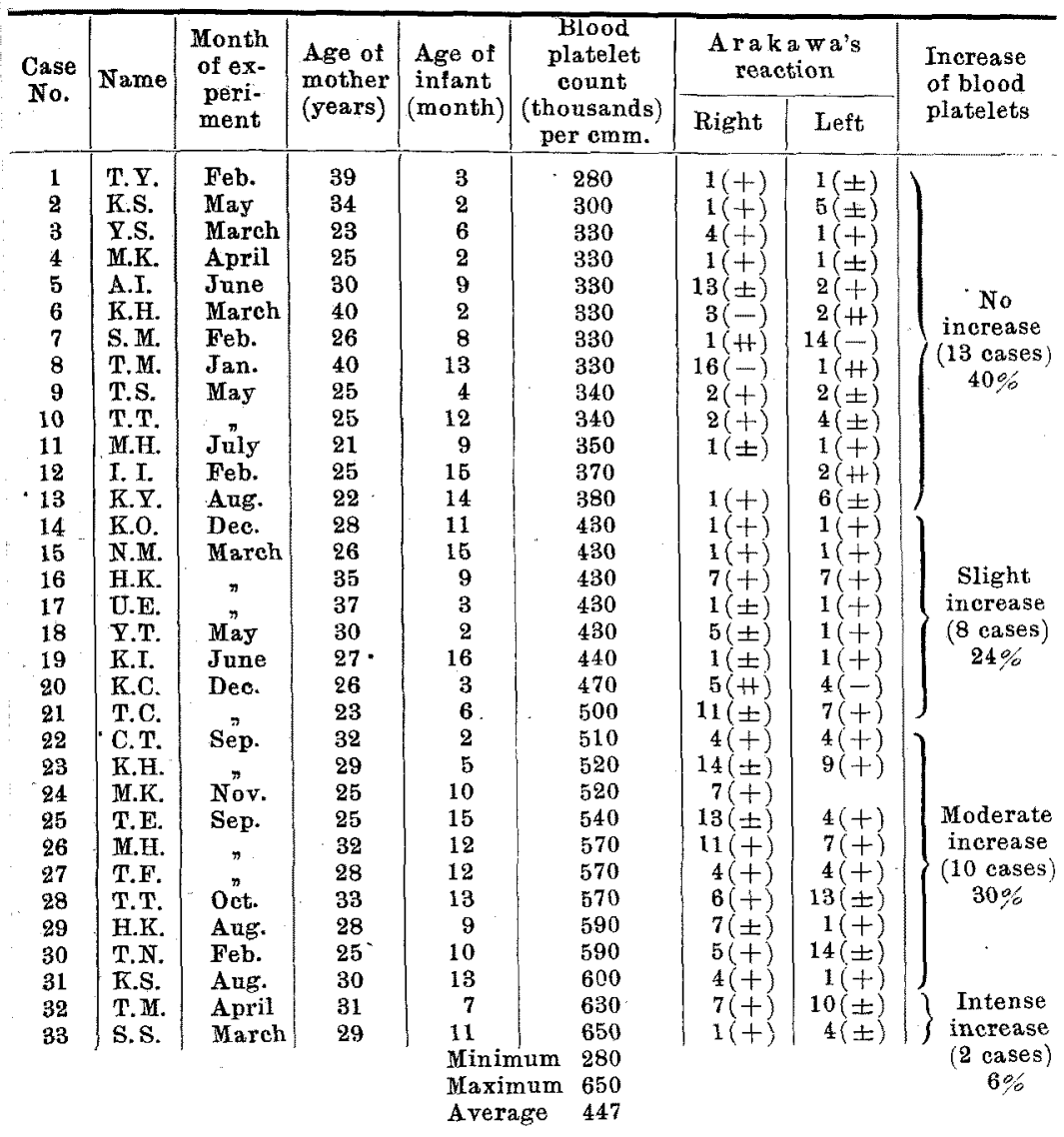

6. Group VI : There were 45 cases belonging to Group VI. In 8 cases $(18 \%)$ out of them the blood platelet count was normal and in the other 37 cases ( $82 \%)$ an increase was seen. 16 cases $(36 \%)$ of them showed a slight increase, 15 cases (33\%) a moderate increase and the remaining 6 cases $(13 \%)$ an intense increase of the count. The average platelet count was 470 thousands (Cf. Table 9).

7. Group VII: There were 41 cases belonging to Group VII. Only 6 cases $(15 \%)$ out of them showed a normal platelet count, and in the other 35 cases (85\%) the count was increased. The reverse is the relation between cases with and without an increase of the platelet 
Table 7.

Blood platelet count of mothers belonging to Group IV.

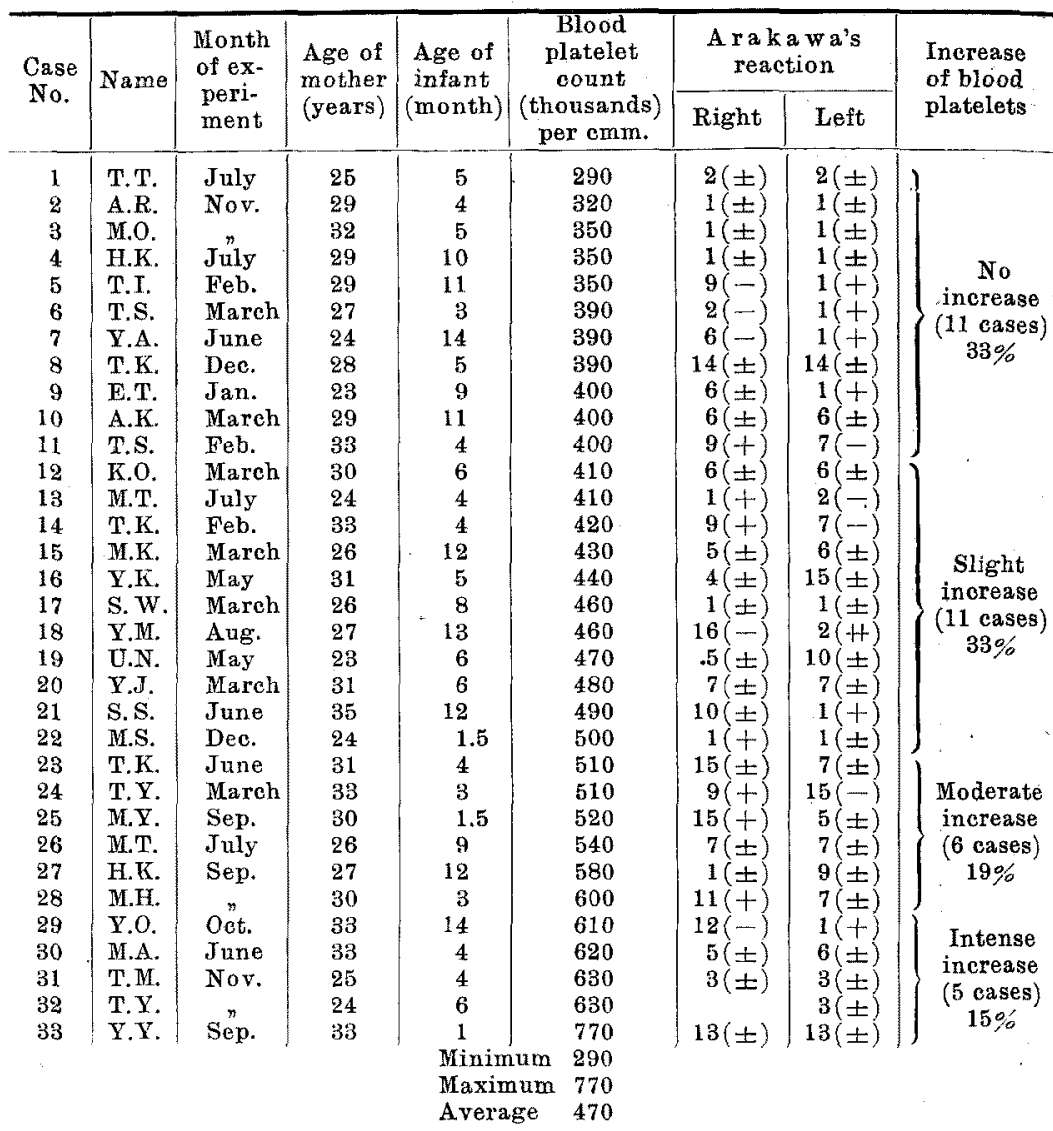

count in Group I and in this group. 15 cases (37\%) of them showed a slight increase, 12 cases (29\%) a moderate increase and the remaining 8 cases $(19 \%)$ an intense increase of the count. The average count in Group VII was 516 thousands (Cf. Table 10).

\section{Comment.}

None of the lactating mothers examined in my enperiment was suffering from beriberi, but there were many mothers who showed an increase of the platelet count-a symptom of B-avitaminosis. And 
TABLE 8.

Blood platelet count of mothers belonging to Group $V$.

\begin{tabular}{|c|c|c|c|c|c|c|c|c|}
\hline \multirow{2}{*}{$\begin{array}{l}\text { Case } \\
\text { No. }\end{array}$} & \multirow[t]{2}{*}{ Name } & \multirow{2}{*}{$\begin{array}{c}\text { Month } \\
\text { of ex- } \\
\text { peri- } \\
\text { ment }\end{array}$} & \multirow{2}{*}{$\begin{array}{l}\text { Age of } \\
\text { mother } \\
\text { (years) }\end{array}$} & \multirow{2}{*}{$\begin{array}{c}\text { Age of } \\
\text { infant } \\
\text { (month) }\end{array}$} & \multirow{2}{*}{\begin{tabular}{|c|} 
Blood \\
platelet \\
count \\
(thousands) \\
per cmm.
\end{tabular}} & \multicolumn{2}{|c|}{$\begin{array}{c}\text { Arakawa's } \\
\text { reaction }\end{array}$} & \multirow{2}{*}{$\begin{array}{l}\text { Inerease } \\
\text { of blood } \\
\text { platelets }\end{array}$} \\
\hline & & & & & & Right & Left & \\
\hline 1 & s. H. & April & 28 & 8. & 250 & $3( \pm)$ & $14(-)$ & \\
\hline 2 & T.S. & July & 24 & 1.5 & 260 & $1( \pm)$ & $7(-)$ & \\
\hline 3 & K.M. & Feb. & 35 & 15 & 260 & $6(-)$ & $6(-)$ & . \\
\hline 4 & H.K. & Jan. & 38 & 10 & 300 & $3(-)$ & $10(-)$ & \\
\hline 5 & A. $\mathbf{Y}$. & May & 28 & 7 & 310 & $10( \pm)$ & $14(-)$ & \\
\hline 6 & T.S. & Dec. & 40 & 15 & 320 & $8(-)$ & $2( \pm)$ & \\
\hline 7 & H.I. & March & 24 & 5 & 350 & $3(-)$ & $1( \pm)$ & No \\
\hline 8 & H.A. & Nov. & 32 & 9 & 350 & $14( \pm)$ & $16(-)$ & increase \\
\hline 9 & H.F. & March & 27 & 9 & 360 & $1(-)$ & $1(-)$ & (16 cases) \\
\hline 10 & J. E. & July & 36 & 16 & 360 & $5( \pm)$ & $16(-)$ & $22 \%$ \\
\hline 11 & T.E. & June & 28 & 16 & 380 & $6(-)$ & $16(-)$ & \\
\hline 12 & Y.U. & Feb. & 39 & 10 & 390 & $6 ?-1$ & $6(-)$ & \\
\hline 13 & C.M. & Dee. & 29 & 4 & 390 & $14(-)$ & $10(-)$ & \\
\hline 14 & S. H. & $\pi$ & 35 & 1.5 & 390 & $8( \pm)$ & $15(-)$ & \\
\hline 15 & S. C. & Jüly & 34 & 2 & 400 & $7(-)$ & $1( \pm)$ & \\
\hline 16 & M.S. & Feb. & 29 & 1.5 & 400 & $11(-)$ & $16(-)$ & \\
\hline 17 & M.K. & June & 27 & 14 & 410 & $2(-)$ & $7(-)$ & \\
\hline 18 & R.K. & Nov. & 27 & 7 & 410 & $12(-)$ & $11( \pm)$ & \\
\hline 19 & Y.I. & Feb. & 25 & 7 & 410 & $15(-)$ & $11(-)$ & \\
\hline 20 & K.I. & July & 27 & 9 & 420 & $11(-)$ & $4(-)$ & \\
\hline 21 & M.A. & March & 33 & 1 & 420 & $15(-)$ & $11(-)$ & \\
\hline 22 & $\overline{\mathbf{Y}} . \mathrm{N}$. & Jan. & 28 & 15 & 440 & $9( \pm)$ & $2(-3)$ & \\
\hline 23 & H.S. & Mareh & 24 & 2 & 440 & $6(-)$ & $6(-)$ & \\
\hline 24 & H.N. & Jan. & 26 & 4 & 450 & $1 \pm$ & $16(-)$ & \\
\hline 25 & R.Y. & April & 22 & 7 & 450 & $6(-)$ & $6(-)$ & \\
\hline 26 & M.T. & July & 30 & 2 & 450 & $12(-)$ & $11( \pm)$ & \\
\hline 27 & M.S. & Jan. & 30 & I1 & 450 & $7( \pm)$ & $16(-)$ & Slight \\
\hline 28 & H.E. & $n$ & 26 & 4 & 450 & $1( \pm)$ & $16(-)$ & increase \\
\hline 29 & N.B. & July & 40 & 14 & 460 & $14(-)$ & $4(-)$ & (25 cases) \\
\hline 30 & Y.S. & Jan. & 24 & 7 & 470 & $1( \pm)$ & $3(-)$ & $\begin{array}{c}240 \text { cases } \\
34^{\circ} \%\end{array}$ \\
\hline 31 & F.G. & Aug. & 22 & 6 & 470 & $10(-)$ & $11(-)$ & \\
\hline 32 & K.K. & Dec. & 29 & 9 & 470 & $7(-)$ & $16(-)$ & \\
\hline 33 & K.S. & Sep. & 35 & 2 & 480. & $13(-)$ & $5( \pm)$ & . \\
\hline 34 & H.U. & Feb. & 30 & 10 & 480 & $4(-)$ & $10(-)$ & \\
\hline 35 & K.S. & July & 26 & 2 & 480 & $11(-)$ & $16(-)$ & \\
\hline 36 & H.O. & Jan. & 21 & 1.5 & 480 & $13(-)$ & $15(-)$ & \\
\hline 37 & R.T. & March & 24. & 15 & 490 & $6( \pm)$ & $6(-)$ & \\
\hline 38 & S.N. & $\#$ & 26 & 4 & 490 & $7(-)$ & $7(-)$ & \\
\hline 39 & J.S. & Dec. & 29 & 14 & 490 & $12(-)$ & $11(-)$ & \\
\hline 40 & T.I. & May & 25 & 1.5 & 490 & $16(-)$ & $6(-)$ & \\
\hline 41 & A.H. & Feb. & 24 & 3 & 490 & $16(-)$ & $11(-)$ & \\
\hline 42 & Y.T. & March & 39 & 6 & 510 & $6( \pm)$ & $4(-)$ & \\
\hline 43 & M.M. & Dec. & 25 & 4 & 510 & $4(-)$ & $15(-)$ & \\
\hline 44 & S. U. & Jan. & 25 & 9 & 510 & $14(-)$ & $11(-)$ & \\
\hline 45 & H.T. & Feb. & 34 & 5 & 510 & $13\{-\}$ & $14(-)$ & \\
\hline 46 & Х.M. & March & 26 & 11 & 520 & $14(-)$ & $6(-)$ & \\
\hline 47 & K.M. & Dee. & 33 & 4 & 520 & $5( \pm)$ & $16(-)$ & \\
\hline 48 & T.K. & 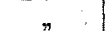 & 23 & 6 & 530 & $10( \pm)$ & $12(-)$ & \\
\hline 49 & F.S. & March & 37 & 2 & 530 & $14( \pm)$ & $15(-)$ & \\
\hline 50 & K.S. & July & 35 & 16 & 530 & $16(-)$ & $6(-)$ & \\
\hline 51 & J. 0. & March & 24 & 1 & 540 & $12(-)$ & $11( \pm)$ & \\
\hline 52 & J.T. & Sep. & 27 & 4 & 540 & $4(-)$ & $4(-)$ & \\
\hline
\end{tabular}


Table 8. Continued.

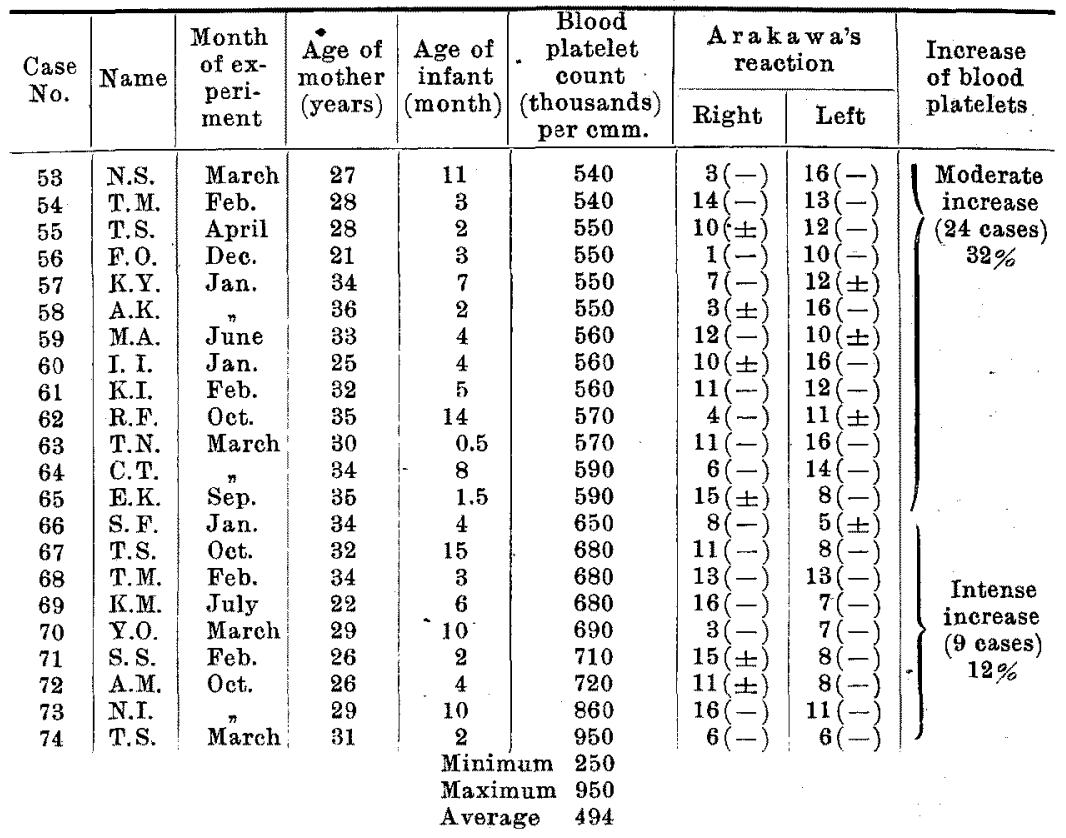

generally the count ran parallel to the intensity of A raka wa's reaction, or the average count was 340 thousands in Group I, 385 thousands in Group II, 447 thousands in Group III, 470 thousands in Group IV; 490 thousands in Group V, 494 thousands in Group VI and 516 thousands in.Group VII. Mothers with an increase of the platelet count were $15 \%$ in Group I, 46\% in Group II, 60\% in Group III, 67\% in Group IV, 78\% in Group V, 82\% in Group VI and $85 \%$ in Group VII (Cf. Tables 4-10).

Table 11 shows a simplification of the results described above, and the parallelism between the intensity of A rakawa's reaction and the blood platelet count-stronger reaction and lower count, and weaker reaction and higher count will be seen at a glance. The ratio of the blood platelet count in the groups of mothers with normal, intermediate and negative Arakawa's reaction was $7: 9: 10$ (Cf. Table 11).

From my results (Cf. Table 11) will be seen again that tha difference of the platelet count is smaller between the groups of intermediate A rakawa's reaction and the group of the negative, than between 
TABle 9.

Blood platelet count of mothers belonging to Group. VI.

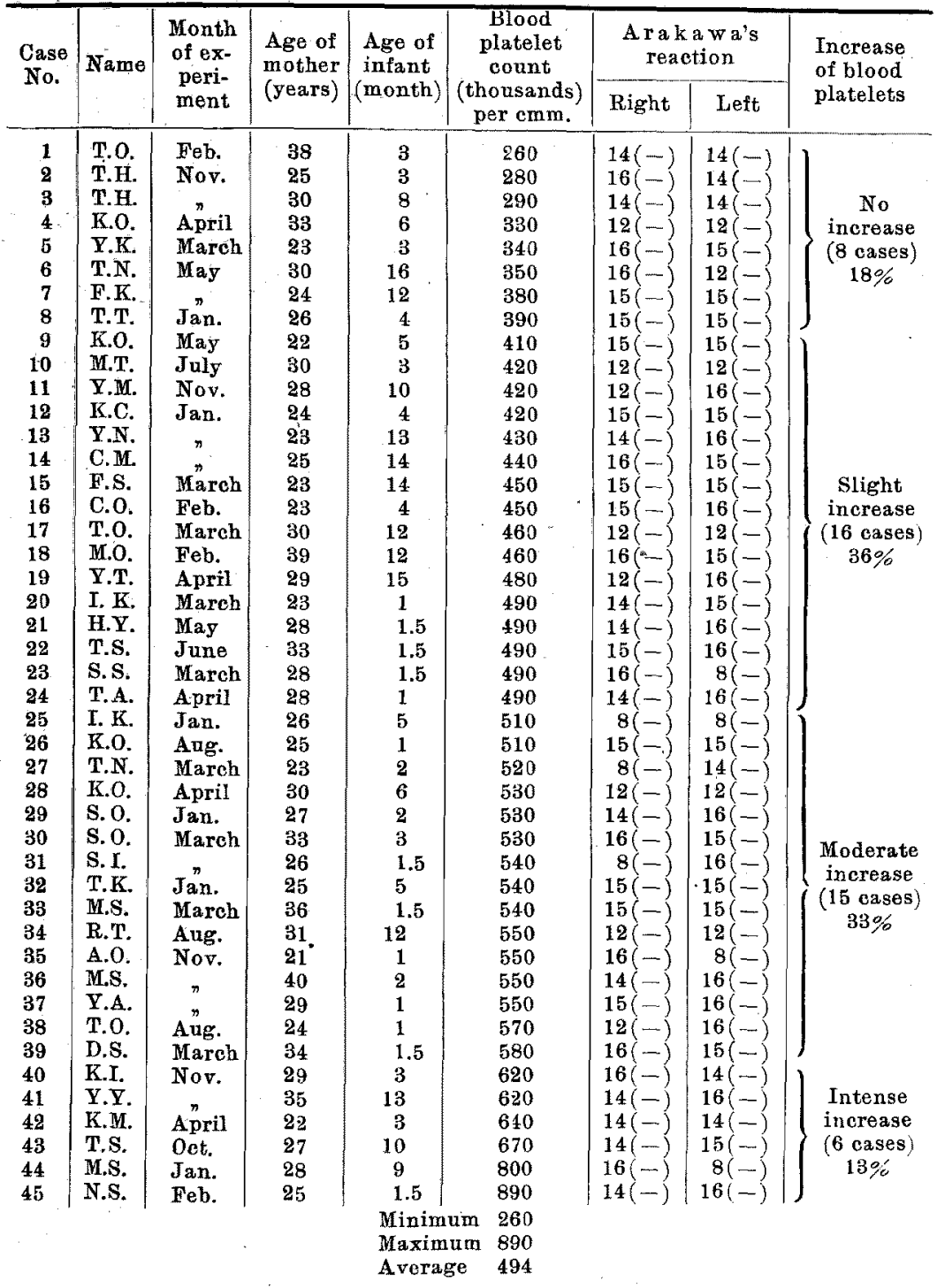

the group of normal A rak a wa's reaction and the groups of the intermediate. 
Table 10.

Blood platelet count of mothers belonging to Group VII.

\begin{tabular}{|c|c|c|c|c|c|c|c|c|}
\hline \multirow{2}{*}{$\begin{array}{l}\text { Case } \\
\text { No. }\end{array}$} & \multirow{2}{*}{ Name } & \multirow{2}{*}{$\begin{array}{l}\text { Month } \\
\text { of ex- } \\
\text { peri- } \\
\text { ment }\end{array}$} & \multirow{2}{*}{$\begin{array}{l}\text { Age of } \\
\text { mother } \\
\text { (years) }\end{array}$} & \multirow{2}{*}{$\begin{array}{l}\text { Age of } \\
\text { infant } \\
\text { (month) }\end{array}$} & \multirow{2}{*}{$\begin{array}{c}\text { Blood } \\
\text { platelet } \\
\text { count } \\
\text { (thousands) } \\
\text { per cmm. }\end{array}$} & \multicolumn{2}{|c|}{$\begin{array}{c}\text { Arakawa's } \\
\text { reaction }\end{array}$} & \multirow{2}{*}{$\begin{array}{l}\text { Increase } \\
\text { of blood } \\
\text { platelets }\end{array}$} \\
\hline & & & & & & Right & Left & \\
\hline 1 & Y.H. & Jan. & 31 & 6 & 290 & $16(-)$ & $16(-)$ & \\
\hline 2 & M.S. & Dec. & 26 & 9 & 310 & $16(-)$ & $16(-)$ & No \\
\hline 3 & A.T. & June & 26 & 3 & 350 & $16(-)$ & $16(-\ldots)$ & increase \\
\hline 4 & N.K. & Feb. & 34 & 14 & 350 & $16(-)$ & $16-?$ & ( 6 cases) \\
\hline 5 & H.K. & June & 29 & 10 & 360 & $16-(-)$ & $16-?$ & $15 \%$ \\
\hline 6 & K. 0 . & Feb. & 27 & 13 & 400 & $16(-)$ & $16(-)$ & \\
\hline 7 & T.T. & March & 27 & 4 & 440 & $16(-)$ & $16(-)$ & \\
\hline 8 & T.I. & Sep. & 33 & 4 & 440 & $16(-)$ & $16(-)$ & \\
\hline 9 & T.E. & March & 22 & 1.5 & 450 & $16(-\cdots)$ & $16(-)$ & \\
\hline 10 & S. I. & Feb. & 23 & 4 & 450 & $16(-)$ & $16(-)$ & \\
\hline 11 & N.S. & June & 31 & 1 & 460 & $16(-)$ & $16(-)$ & \\
\hline 12 & K.M. & Feb. & 29 & 1 & 460 & $16(-)$ & $16(-)$ & Slight \\
\hline 13 & K.S. & June & 22 & 3 & 470 & $16(-)$ & $16(-)$ & increase \\
\hline 14 & A.T. & $n$ & 30 & 5 & 470 & $16(--)$ & $16(-)$ & (15 cases) \\
\hline 15 & Y.A. & Nov. & 38 & 7 & 470 & $16(-)$ & $16(-)$ & $37 \%$ \\
\hline 16 & N.M. & Feb. & 27 & 12 & 480 & $16(-)$ & $16(-)$ & \\
\hline 17 & K.K. & $n$ & 30 & 12 & 480 & $16(-)$ & $16(-)$ & \\
\hline 18 & A.I. & May & 28 & 1.5 & 480 & $16(-)$ & $16(-)$ & \\
\hline 19 & T.B. & $n$ & 35 & 0.5 & 480 & $16(-)$ & $16(-)$ & \\
\hline 20 & T. H. & Dec. & 24 & 11 & 490 & $16(-)$ & $16(-)$ & \\
\hline 21 & S.Y. & March & 24 & 6 & 490 & $16(-)$ & $16(-)$ & \\
\hline 22 & M.H. & Feb. & 30 & 11 & 510 & $16(-)$ & $16(-)$ & \\
\hline 23 & Y.A. & Jan. & 28 & 5 & 520 & $16(-)$ & $16(-)$ & \\
\hline 24 & T.A. & Sep. & 21 & 3 & 540 & $16(-)$ & $16(-)$ & \\
\hline 25 & Y.Y. & Jan. & 24 & 1 & 540 & $16(-)$ & $16(-)$ & \\
\hline 26 & Y.W. & $n$ & 32 & 3 & 540 & $16(-)$ & $16(-)$ & Moderate \\
\hline 27 & A. 0 . & & 26 & 0.5 & 550 & $16(-)$ & $16(-)$ & increase \\
\hline 28 & Y.S. & March & 27 & 3 & 560 & $16(-)$ & $16(-)$ & (12 cases) \\
\hline 29 & A.I. & April & 35 & 9 & 560 & $16(-)$ & $16(--)$ & $29 \%$ \\
\hline 30 & I. M. & Jan. & 23 & 2 & 560 & $16(-)$ & $16(-)$ & \\
\hline 31 & T.N. & Feb. & 25 & 10 & 570 & $16(-)$ & $16(-)$ & \\
\hline 32 & M.K. & Nov. & 25 & 9 & 590 & $16(-)$ & & \\
\hline 33 & K.S. & $\pi$ & 26 & 7 & 600 & $16(-)$ & $16(-)$ & \\
\hline 34 & H.K. & Jan. & 29 & 2 & 610 & $16(-)$ & $16(-)$ & \\
\hline 35 & M.O, & Sep. & 27 & 1 & 640 & $16(-)$ & $16(-)$ & \\
\hline 36 & M.K. & Jan. & 40 & 1 & 660 & $16(-)$ & $16(-)$ & Intense \\
\hline 37 & M.A. & $\pi$ & 27 & 2 & 670 & $16(-)$ & $16(-)$ & increase \\
\hline 38 & C.T. & Sep. & 41 & 8 & 680 & $16(-)$ & $16(-)$ & ( 8 cases) \\
\hline 39 & S.S. & Nov. & 38 & 15 & 680 & $16(-)$ & $16(-)$ & $19 \%$ \\
\hline 40 & C. T. & April & 25 & 4 & 740 & $16(-)$ & $16(-)$ & \\
\hline 41 & T.S. & Oet. & 32 & 12 & 760 & $16(-)$ & $16(-)$ & \\
\hline & & & & Min & 290 & & & \\
\hline & & & & Max & um 760 & & & \\
\hline & & & & Aver & 516 & & & \\
\hline
\end{tabular}

It is now an indubitable fact that mothers secreting milk negative to Arakaw a's reaction are in a state of avitaminosis B. From the reports published by $\mathrm{Id} o,{ }^{9)} \mathrm{Kub} o{ }^{10)} \mathrm{Nakamura}{ }^{11)}$ and Iijima,${ }^{12)}$

9) Y. Id o, Fukuoka Ikwadaigaku Zasshi, 1912, 6, 217.

10) T. K ub o, Tokyo Iji Shinshi, 1912, 1417.

11) M. Naka mu ra, Nippon Naikwagakkwai Zasshi, 1925, 13, 317.

12) R. Iiji ma, Rinsho Byorigaku-Ketsuekigakkwai Zasshi, 1935, 4, 531. 
Table 11.

Relation between A rakawa's reaction and blood platelet count of lactating mothers.

\begin{tabular}{|c|c|c|c|c|c|}
\hline $\begin{array}{c}\text { Platelets } \\
\text { (thousands) }\end{array}$ & $\begin{array}{l}200-400 \\
\text { No } \\
\text { increase }\end{array}$ & $\begin{array}{l}400-500 \\
\text { Slight } \\
\text { increase }\end{array}$ & $\begin{array}{l}500-600 \\
\text { Moderate } \\
\text { increase }\end{array}$ & $\begin{array}{c}600 \\
\text { Intense } \\
\text { increase }\end{array}$ & $\begin{array}{l}\text { Average } \\
\text { count of } \\
\text { blood pla- } \\
\text { telet count } \\
\text { (thousands) } \\
\text { per cmm. }\end{array}$ \\
\hline $\begin{array}{c}\mathrm{I} \\
27 \text { eases }\end{array}$ & $\begin{array}{c}84 \% \\
\text { (28 cases) }\end{array}$ & $\begin{array}{c}15 \% \\
(4 \text { cases })\end{array}$ & 0 & 0 & 340 \\
\hline $\begin{array}{l}I I+I I I \\
46 \text { cases }\end{array}$ & $\left(20^{43} n\right)$ & $\left(13^{28 \pi}\right)$ & $\begin{array}{c}24 \% \\
(11 \text { cases) }\end{array}$ & $\begin{array}{c}5 \% \\
(2 \text { cases) }\end{array}$ & 431 \\
\hline $\begin{array}{c}I V+V \\
107 \text { cases }\end{array}$ & $\left(27^{25 n}, n\right)$ & $\left(36^{34} "\right.$, & $\left(30^{24} \pi\right)$ & $\left(14^{13} n\right)$ & 487 \\
\hline $\begin{array}{l}V I+V I I \\
86 \text { cases }\end{array}$ & $\left(14^{16} \%\right)$ & $\left(31^{36} "\right)$ & $\left(27^{32 n} n\right)$ & $\left(14^{16 n},\right)$ & 504 \\
\hline
\end{tabular}

an increase of the blood platelet count is a symptom of beriberi or Bavitaminosis. And J. Kimura ${ }^{1 / 2) 3}$ said that the high count of blood platelets in apparently healthy mothers with negative Arakawa's reaction was an early sign of $B$-avitaminosis. The fact mentioned above will also be seen from the present paper.

When one compares my own results with J. Ki mu ra's (Cf. Table 12), one will find that the blood platelet count in lactating mothers with normal Arakawa's reaction is larger in the former that the lat-

TABle 12.

Comparison of average count of blood platelets between

J. Kimura's and own results.

\begin{tabular}{|c|c|c|c|c|}
\hline & & $\begin{array}{c}\text { Strongly Arakawa- } \\
\text { positive cases }\end{array}$ & $\begin{array}{l}\text { Cases with } \\
\text { intermediate } \\
\text { Arakawa's } \\
\text { reaction }\end{array}$ & $\begin{array}{c}\text { Completely (or } \\
\text { almost completely) } \\
\text { Arakawa-negative } \\
\text { cases }\end{array}$ \\
\hline \multirow{3}{*}{ 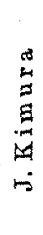 } & $\begin{array}{l}\text { 1st publication } \\
\text { (100 cases) }\end{array}$ & $\begin{array}{c}256,000 \\
(52 \text { in all })\end{array}$ & & $\begin{array}{c}575,000 \\
(48 \text { in all) }\end{array}$ \\
\hline & $\begin{array}{l}\text { 2nd prablication } \\
(100 \rightarrow)\end{array}$ & $\begin{array}{c}267,000 \\
(11, n)\end{array}$ & $\begin{array}{c}428,000 \\
(4 \pm \text { in all) }\end{array}$ & $\begin{array}{c}586,000 \\
(45 \% n)\end{array}$ \\
\hline & $\begin{array}{l}\text { 3rd publication } \\
\quad(125 \pi)\end{array}$ & $\begin{array}{c}277,000 \\
4 \pi n)\end{array}$ & $\begin{array}{c}430,000 \\
(109, n)\end{array}$ & $\begin{array}{c}678,000 \\
(12 * ")\end{array}$ \\
\hline & $\begin{array}{r}\text { My own } \\
266 \text { cases }\end{array}$ & $\begin{array}{c}340,000 \\
(27, \quad)\end{array}$ & $\begin{array}{c}467,000 \\
(153 n,)\end{array}$ & $\begin{array}{l}\because 504,000 \\
(86 \% \pi)\end{array}$ \\
\hline
\end{tabular}

*Arakawa's reaction ( \pm$) 5^{\prime}$ was included here as in the reports $J$. K im $\mathrm{m}$ ra tried. 
ter, but that the count in mothers with negative A rakawa's reaction is smaller in the former than in the latter (Cf. Table 12).

Using Lam pert's thrombocyte counting method, I waited longer than five minutes after the diluted blood was placed in the counting chamber. The difference of the results may be due to a difference of the technique used, yet the difference was small compared with that between La m pert's own figures of normal count and my own average of 30 healthy women. Besides, the relation as a whole-the relation between Arakawa's reaction and platelet count-is exactly the same in my own trial as well as in $\mathrm{J}$. Ki mura's experiment.

\section{Summary.}

I examined the blood platelet count of 266 apparently healthy lactating mothers with different Arakaw a's reaction.

The platelet count of 27 Arakawa-positive mothers was within normal limits in $84 \%$ of the cases, and only $15 \%$ showed a slight increase of the count, the average count being 340 thousands in all the Arakawa-positive cases. The count of Groups II and III (the groups of the better intermediate A ra ka w a's reaction) showed normal count in $43 \%$ of the cases, a slight increase in $28 \%$, a moderate increase in $24 \%$ and in intense or remarkable increase in $5 \%$, the average count being 431 thousands. The count of Groups III and IV (the groups of the worse intermediate A ra ka wa's reaction) showed a normal count in $25 \%$, a slight increase in $34 \%$, a moderate increase in $24 \%$ and a remarkable increase in $13 \%$, the average count being 487 thousands. The count of Groups VI and VII (the groups of completely or almost completely negative Arakawa's reaction) showed a normal count in only $16 \%$, a slight increase in $36 \%$, a moderate increase in $32 \%$ and a remarkable increase in $16 \%$, the average count being 504 thousands (Cf. Table 11). Thus, the platelet count ran parallel to the intensity of Arakawa's reaction.

\section{Conclusion.}

In the present paper I performed a further study on the relationship between the blood platelet count and A rakawa's reaction in apparently healthy lactating mothers. The blood platelet count was low (or within the normal limits) in most of Arakawa-positive mothers and was more or less high (or over the normal limits) in Arakawa-negative mothers; the results obtained by J. Kimura in 1934 and 1935 were thus confirmed by the present paper again. We can say on principle that the weaker the Araka wa reaction, the higher the blood platelet count is. 